\title{
Cell-Free DNA Methylation of Selected Genes Allows for Early Detection of the Major Cancers in Women
}

\author{
Sandra P. Nunes ${ }^{1,2}\left(\right.$, Catarina Moreira-Barbosa ${ }^{1}$, Sofia Salta ${ }^{1} \oplus$, Susana Palma de Sousa ${ }^{3}$, \\ Inês Pousa ${ }^{4}$, Júlio Oliveira ${ }^{4}$, Marta Soares ${ }^{4}$, Licínio Rego ${ }^{5}$, Teresa Dias ${ }^{5}$, Jéssica Rodrigues ${ }^{6}$, \\ Luís Antunes ${ }^{6}$, Rui Henrique ${ }^{1,7,8}$ (D) and Carmen Jerónimo ${ }^{1,8, *(D)}$ \\ 1 Cancer Biology \& Epigenetics Group-Research Center, Portuguese Oncology Institute of Porto (CI-IPOP), \\ 4200-072 Porto, Portugal; sandra22nunes@hotmail.com (S.P.N.); \\ catarina.moreira.barbosa@gmail.com (C.M.-B.); sofia.salta@ipoporto.min-saude.pt (S.S.); \\ rmhenrique@icbas.up.pt (R.H.) \\ 2 Master in Oncology, Institute of Biomedical Sciences Abel Salazar, University of Porto (ICBAS-UP), \\ 4050-313 Porto, Portugal \\ 3 Breast Cancer Clinic and Department of Medical Oncology, Portuguese Oncology Institute of Porto, \\ 4200-072 Porto, Portugal; susana.sousa@ipoporto.min-saude.pt \\ 4 Lung Cancer Clinic and Department of Medical Oncology, Portuguese Oncology Institute of Porto, \\ 4200-072 Porto, Portugal; ines.ruiz@ipoporto.min-saude.pt (I.P.); julio.oliveira@ipoporto.min-saude.pt (J.O.); \\ martasoares@ipoporto.min-saude.pt (M.S.) \\ 5 Digestive Tract Pathology Clinic and Surgical Oncology, Portuguese Oncology Institute of Porto, \\ 4200-072 Porto, Portugal; licinio@ipoporto.min-saude.pt (L.R.); teresa.dias@ipoporto.min-saude.pt (T.D.) \\ 6 Department of Epidemiology, Portuguese Oncology Institute of Porto, 4200-072 Porto, Portugal; \\ jessica.rocha.rodrigues@ipoporto.min-saude.pt (J.R.); luis.antunes@ipoporto.min-saude.pt (L.A.) \\ 7 Department of Pathology, Portuguese Oncology Institute of Porto, 4200-072 Porto, Portugal \\ 8 Department of Pathology and Molecular Immunology, Institute of Biomedical Sciences Abel Salazar, \\ University of Porto (ICBAS-UP), 4050-313 Porto, Portugal \\ * Correspondence: carmenjeronimo@ipoporto.min-saude.pt or cljeronimo@icbas.up.pt; Tel.: +351-225084000; \\ Fax: +351-225084047
}

Received: 24 August 2018; Accepted: 25 September 2018; Published: 26 September 2018

\begin{abstract}
Background: Breast (BrC), colorectal (CRC) and lung (LC) cancers are the three most common and deadly cancers in women. Cancer screening entails an increase in early stage disease detection but is hampered by high false-positive rates and overdiagnosis/overtreatment. Aberrant DNA methylation occurs early in cancer and may be detected in circulating cell-free DNA (ccfDNA), constituting a valuable biomarker and enabling non-invasive testing for cancer detection. We aimed to develop a ccfDNA methylation-based test for simultaneous detection of BrC, CRC and LC. Methods: CcfDNA from BrC, CRC and LC patients and asymptomatic controls were extracted from plasma, sodium-bisulfite modified and whole-genome amplified. APC, FOXA1, MGMT, RARß2, RASSF1A, SCGB3A1, SEPT9, SHOX2 and SOX17 promoter methylation levels were determined by multiplex quantitative methylation-specific PCR. Associations between methylation and standard clinicopathological parameters were assessed. Biomarkers' diagnostic performance was also evaluated. Results: A "PanCancer" panel (APC, FOXA1, RASSF1A) detected the three major cancers with $72 \%$ sensitivity and $74 \%$ specificity, whereas a "CancerType" panel (SCGB3A1, SEPT9 and SOX17) indicated the most likely cancer topography, with over $80 \%$ specificity, although with limited sensitivity. Conclusions: CcfDNA's methylation assessment allows for simultaneous screening of $\mathrm{BrC}, \mathrm{CRC}$ and LC, complementing current modalities, perfecting cancer suspects' triage, increasing compliance and cost-effectiveness.
\end{abstract}

Keywords: breast cancer; colorectal cancer; lung cancer; DNA methylation; epigenetic biomarker; cell-free DNA; liquid biopsy; detection 


\section{Introduction}

Breast ( $\mathrm{BrC})$, colorectal (CRC) and lung ( $\mathrm{LC})$ cancers are the most incident and lethal malignancies affecting women from developed countries [1]. Over the last years, $\mathrm{BrC}$ incidence increased, fueled by mammography-based screening [1], which endows about $85 \%$ sensitivity and $90 \%$ specificity [2]. Nonetheless, sensitivity is much lower in dense breasts (over $70 \%$ of the breast tumors are missed in dense breasts) [3] and, although mammography may reduce mortality by $28-45 \%$ [4], it entails overdiagnosis (an estimated 11\% in screening programs) and consequent overtreatment [5]. About $95 \%$ of CRC patients might be cured through surgery if diagnosed early and several screening protocols coexist [6]. Colonoscopy-based screening is performed every ten years after the age of 50 years [7], displaying high sensitivity and the main advantage of removing lesions at the time of detection [7]. However, it is an invasive and costly procedure, requiring unpleasant bowel preparation, sedation, the risk of bowel perforation, bleeding, and low compliance [7]. Fecal occult blood (FOBT) and fecal immunochemical (FIT) testing for triage of patients requiring subsequent colonoscopy are less-invasive options which have been shown to reduce CRC-related-mortality [8]. Nevertheless, the high false-positive rate is a limitation, since bleeding might derive from non-neoplastic disorders such as hemorrhoidal or inflammatory bowel diseases [8]. LC has become a major cause of cancer-related death among women in more developed regions [1], since $75 \%$ of the cases are diagnosed at advanced stages [9]. Low-dose computed tomography (LD-CT) has been suggested for LC screening. The National Lung Screening Trial comparing the performance of LD-CT with chest x-ray for LC screening found a $20 \%$ decrease in LC-related mortality in the LD-CT group, although without additional confirmatory studies [10] and at the cost of $96.4 \%$ false positive rate [11]. Thus, although current screening strategies for BrC, CRC and LC are beneficial, they may impact negatively on health systems management and women's quality of life. Hence, the development of better pre-screening methods, which might prevent selection of invasive/costly screening tests, avoiding overdiagnosis/overtreatment and unnecessary procedures is necessary.

Aberrant promoter methylation of cancer-related genes is common at the earliest steps of carcinogenesis, thus constituting a source for promising cancer detection biomarkers [12]. This is a stable genomic alteration which might be detected in serum/plasma circulating cell-free DNA (ccfDNA) [13], that might even portray tumor heterogeneity better than tissue biopsies [14]. Several methylated genes have been proposed as tumor biomarkers for BrC, CRC or LC detection, including APC, RAR 32 and RASSF1A [15-18]. Although SEPT9 and PTGER4/SHOX2 methylation-based non- or minimally invasive tests are already commercially available for CRC and LC detection, respectively $[19,20]$, they have limited sensitivity. Furthermore, a recent study using methylation scores displayed $87 \%$ sensitivity for advanced cancer detection $(\mathrm{BrC}, \mathrm{CRC}$, non-small cell LC and melanoma) with $100 \%$ specificity, predicting also the cancer type in $76 \%$ of cases [21]. Thus, we aimed to develop a sensitive and specific methylation-based test enabling the simultaneous detection of $\mathrm{BrC}, \mathrm{CRC}$ and $\mathrm{LC}$ in women using ccfDNA. For that purpose, promoter methylation levels of 9 genes (APC, FOXA1, MGMT, RARß2, RASSF1A, SCGB3A1, SEPT9, SHOX2 and SOX17), selected based on our previous experience $[16,18]$ and extensive literature review $[15,17,22-29]$, were assessed by multiplex quantitative specific PCR (qMSP) in ccfDNA extracted from plasma samples of female subjects.

\section{Results}

\subsection{Clinical and Pathological Data}

This study included 253 female patients with $\operatorname{BrC}(n=108)$, CRC $(n=72)$ or LC $(n=73)$ and 103 female asymptomatic controls (AC). Detailed clinical and pathological characterization is provided in Table 1. Globally, the median age of cancer patients significantly differed from that of controls $(p<0.0001)$, and, thus, correlations between age and gene promoter methylation levels were assessed stratifying for ACs and cancer patients. Although SOX17 promoter's methylation levels correlated with controls' 
age ( $\mathrm{R}=0.225, p=0.009)$, this was not observed in cancer patients and no other significant correlations were disclosed.

Table 1. Clinicopathological features of $\mathrm{BrC}, \mathrm{CRC}$ and LC patients and ACs enrolled in this study.

\begin{tabular}{|c|c|c|}
\hline Clinicopathological Features & AC & Cancer Patients \\
\hline Number & 103 & 253 \\
\hline \multirow[t]{2}{*}{ Age median (range) } & $52(45-65)$ & $63(29-93)$ \\
\hline & & Breast Cancer \\
\hline Histological Type & \multirow{5}{*}{ n.a. } & \\
\hline Invasive Carcinoma, no special type (NST) & & 80 \\
\hline Invasive lobular carcinoma & & 12 \\
\hline Ductal carcinoma in situ & & 7 \\
\hline Other invasive carcinoma subtypes ${ }^{a}$ & & 9 \\
\hline \multicolumn{3}{|l|}{ Primary Tumor $(\mathrm{T})$} \\
\hline Tis & \multirow{3}{*}{ n.a. } & 7 \\
\hline $\mathrm{T} 1 \& \mathrm{~T} 2$ & & 95 \\
\hline $\mathrm{T} 3 \& \mathrm{~T} 4$ & & 6 \\
\hline \multicolumn{3}{|l|}{ Regional lymph node (N) } \\
\hline No & \multirow[t]{2}{*}{ n.a. } & 65 \\
\hline $\mathrm{N}+$ & & 43 \\
\hline \multicolumn{3}{|l|}{ Distant metastasis (M) } \\
\hline M0 & \multirow[t]{2}{*}{ n.a. } & 105 \\
\hline M1 & & 3 \\
\hline \multicolumn{3}{|l|}{ Clinical Stage } \\
\hline 0 & \multirow{3}{*}{ n.a. } & 7 \\
\hline $\mathrm{I} / \mathrm{II}$ & & 88 \\
\hline III/IV & & 13 \\
\hline & & Colorectal Cancer \\
\hline Histological Type & \multirow{4}{*}{ n.a. } & \\
\hline Premalignant Lesions ${ }^{b}$ & & 3 \\
\hline Adenocarcinoma (all subtypes) & & 68 \\
\hline Neuroendocrine carcinoma & & 1 \\
\hline \multicolumn{3}{|l|}{ Tumor location } \\
\hline Proximal colon & \multirow{3}{*}{ n.a. } & 23 \\
\hline Distal colon & & 30 \\
\hline Rectum & & 19 \\
\hline \multicolumn{3}{|l|}{ Primary tumor $(\mathrm{T})^{\mathrm{c}}$} \\
\hline Tis & \multirow{3}{*}{ n.a. } & 3 \\
\hline $\mathrm{T} 1 \& \mathrm{~T} 2$ & & 18 \\
\hline $\mathrm{T} 3 \& \mathrm{~T} 4$ & & 49 \\
\hline \multicolumn{3}{|l|}{ Regional lymph node $(\mathrm{N})^{\mathrm{c}}$} \\
\hline No & \multirow[t]{2}{*}{ n.a. } & 37 \\
\hline $\mathrm{N}+$ & & 33 \\
\hline \multicolumn{3}{|l|}{ Distant metastasis (M) } \\
\hline M0 & \multirow[t]{2}{*}{ n.a. } & 66 \\
\hline M1 & & 6 \\
\hline \multicolumn{3}{|l|}{ Clinical Stage } \\
\hline 0 & \multirow{3}{*}{ n.a. } & 3 \\
\hline $\mathrm{I} / \mathrm{II}$ & & 34 \\
\hline III/IV & & 35 \\
\hline
\end{tabular}


Table 1. Cont.

\begin{tabular}{|c|c|c|}
\hline Clinicopathological Features & AC & Cancer Patients \\
\hline & & Lung Cancer \\
\hline Histological Type & \multirow{6}{*}{ n.a. } & \\
\hline Non-small cell lung carcinoma (NSCLC) & & \\
\hline Adenocarcinoma & & 56 \\
\hline Other NSCLC subtypes ${ }^{d}$ & & 8 \\
\hline Small-cell lung carcinoma (SCLC) & & 8 \\
\hline Carcinoid tumor & & 1 \\
\hline Primary Tumor $(\mathrm{T})^{\mathrm{e}}$ & \multirow{3}{*}{ n.a. } & \\
\hline $\mathrm{T} 1$ & & 18 \\
\hline $\mathrm{T} 2 / \mathrm{T} 3 / \mathrm{T} 4$ & & 51 \\
\hline \multicolumn{3}{|l|}{ Regional lymph node $(\mathrm{N})^{\mathrm{f}}$} \\
\hline No & n.a. & 27 \\
\hline $\mathrm{N}+$ & & 45 \\
\hline Distant metastasis (M) & \multirow{3}{*}{ n.a. } & \\
\hline M0 & & 36 \\
\hline M1 & & 37 \\
\hline \multirow[t]{2}{*}{ Clinical StageI/II } & \multirow{3}{*}{ n.a. } & \\
\hline & & 21 \\
\hline III/IV & & 52 \\
\hline
\end{tabular}

a Includes medullary, mucinous and mixed type carcinoma (invasive carcinoma, NST and micropapillary carcinoma);

${ }^{b}$ Includes tubulovillous adenoma with high-grade dysplasia and intramucosal adenocarcinoma; ${ }^{\mathrm{C}}$ No information available in 2 cases; ${ }^{\mathrm{d}}$ Includes squamous cell carcinoma and large-cell neuroendocrine carcinoma; ${ }^{\mathrm{e}}$ No information available in 4 cases; ${ }^{\mathrm{f}}$ Not possible to determine in 1 case; AC, Asymptomatic Control; n.a.: non-applicable

\subsection{Gene Promoter Methylation Levels in ccfDNA}

$A P C, F O X A 1, R A S S F 1 A$ and SCGB3A1 promoters depicted significantly higher methylation levels in $\operatorname{BrC}$ patients than in controls $(p<0.0001, p=0.0063, p=0.0003$ and $p=0.0245$, respectively) (Figure 1 , Supplementary Table S1). Nonetheless, no significant differences were found for MGMT, RAR $\beta 2$, SHOX2, SEPT9 and SOX17.

In CRC patients, APC, FOXA1, RAR $\beta 2$, RASSF1A, SCGB3A1, SEPT9 and SOX17 methylation levels were significantly higher than in controls $(p=0.005, p<0.0001, p=0.009, p=0.012, p=0.003$, $p=0.001$ and $p=0.007$, respectively) (Figure 1, Supplementary Table S1), although no differences were apparent for MGMT and SHOX2 methylation levels.

Concerning LC, significantly higher methylation levels compared to controls were disclosed for $A P C$, FOXA1, RAR $\beta 2, R A S S F 1 A$ and SOX17 ( $p<0.0001$ for all genes), only (Figure 1, Supplementary Table S1). 

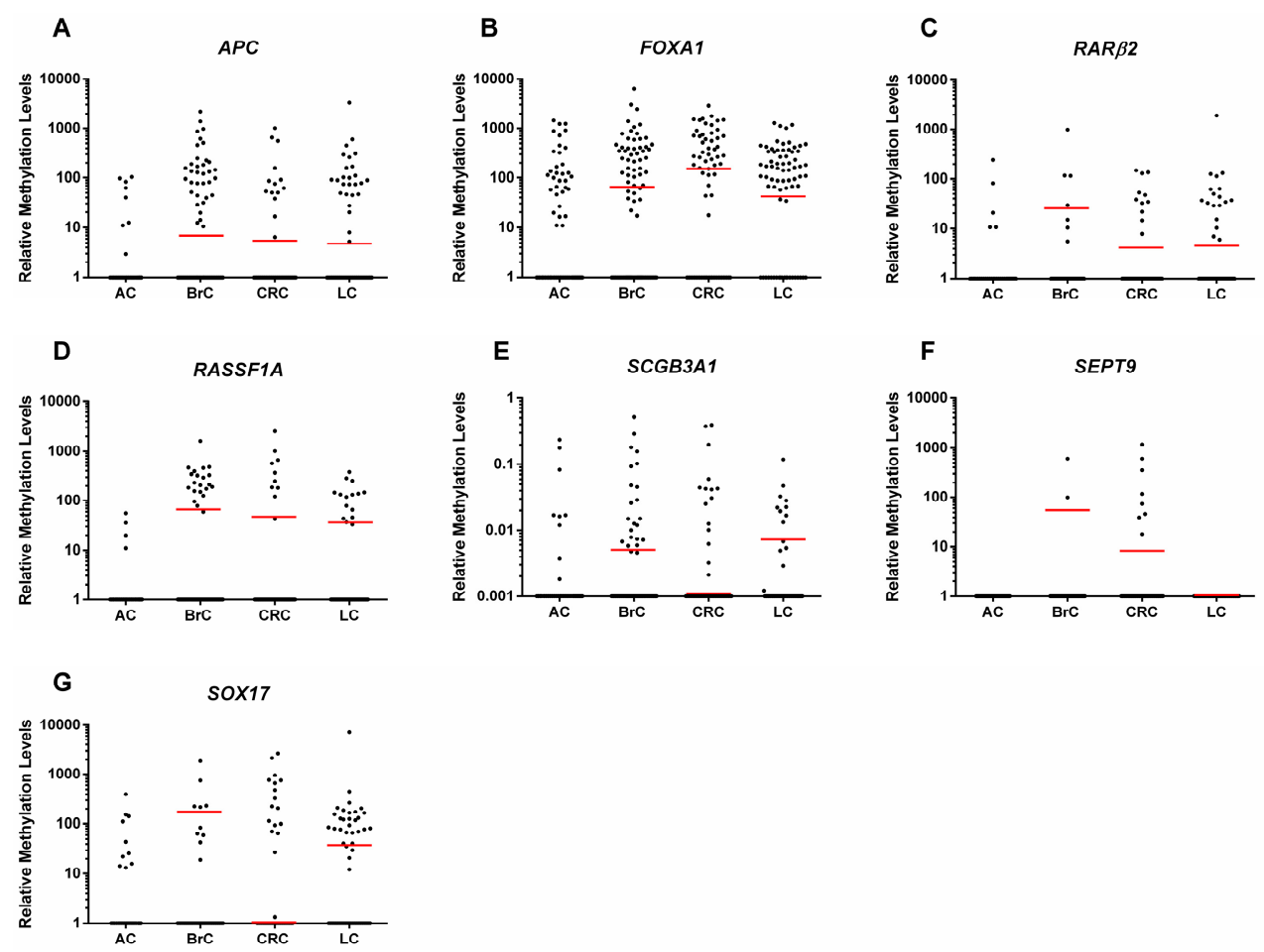

Figure 1. Scatter plot of the distribution of (A) APC, (B) FOXA1, (C) RAR $32,(\mathbf{D}) R A S S F 1 A$, (E) SCGB3A1, (F) SEPT9 and (G) SOX17 relative methylation levels [(gene/ $\beta$-Actin) $\times 1000$ ] of breast cancer $(\mathrm{BrC})$ $(n=108)$, colorectal cancer (CRC) $(n=72)$, lung cancer (LC) samples $(n=73)$ and asymptomatic controls (ACs) samples $(n=103)$. Red horizontal lines represent cut-off values.

\subsection{Association Between Promoters' Methylation Levels and Clinicopathological Features}

Methylation levels of tested gene promoters associated with several clinicopathological features. Specifically, in BrC patients, RASSF1A methylation levels significantly differed between progesterone receptor $(\mathrm{PR})+$ and $\mathrm{PR}$ - tumors $(p=0.031)$ (Figure 2(A1)), whereas $R A R \beta 2$ promoter methylation levels were higher in node-positive than in node-negative $\operatorname{BrC}$ patients $(p=0.009)$ (Figure 2(A2)). Moreover, in CRC patients, SEPT9 promoter methylation levels were significantly higher in patients with stage IV or distant metastatic disease (M1) $(p<0.01$, in all comparisons) (Figure 2(B2)). Similar results were depicted for APC, SHOX2 and SOX17 promoter methylation in metastatic vs. non-metastatic CRC patients ( $p=0.0276, p=0.0107$ and $p=0.0242$, respectively), although no differences were found for stage (Figure 2B). Concerning LC, significantly higher $A P C$ and $R A R \beta 2$ promoter methylation levels were apparent in small-cell lung cancer (SCLC) patients compared to those with adenocarcinoma $(p=0.005$ and $p=0.035$, respectively) (Figure 2(C1,C2)). Moreover, node-positive LC patients displayed higher RASSF1A methylation levels than node-negative LC patients ( $p=0.018$, Figure 2(C3)), whereas higher $S O X 17$ promoter methylation was observed in patients with systemic metastization $(p=0.029)$ (Figure 2(C4)). 
A 1

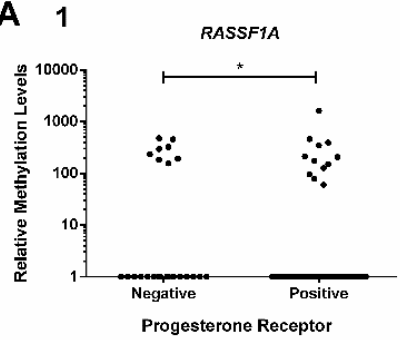

B 1
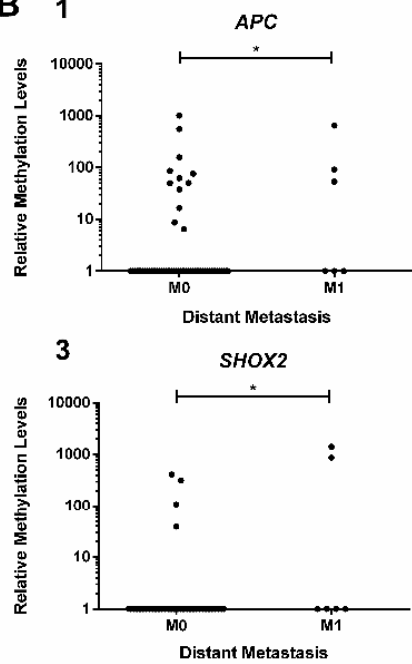

C 1

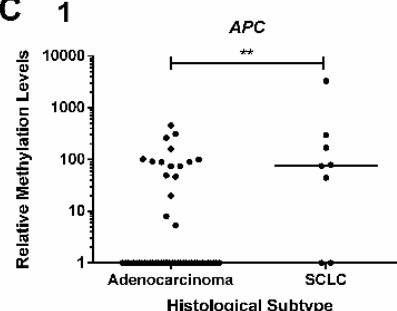

Histological Subtype

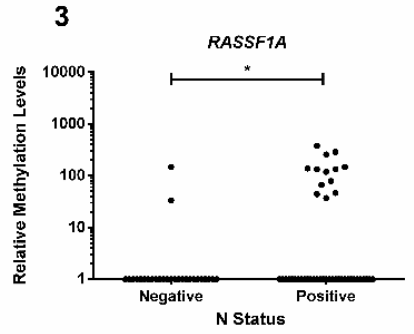

2

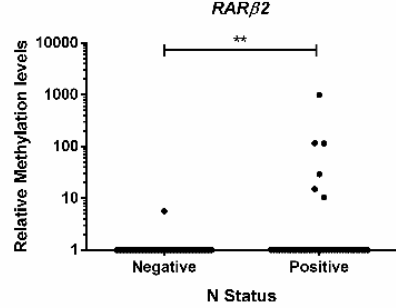

2
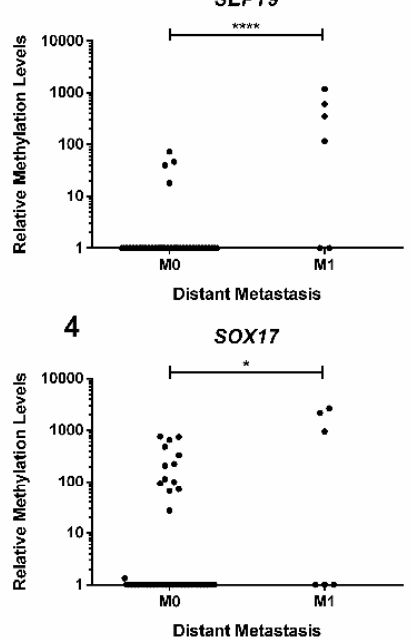

2

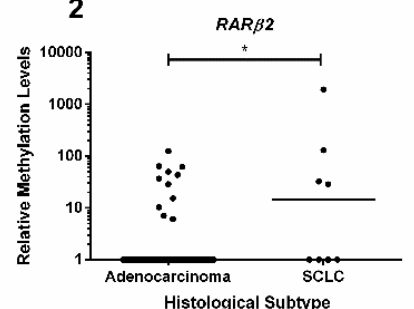

4

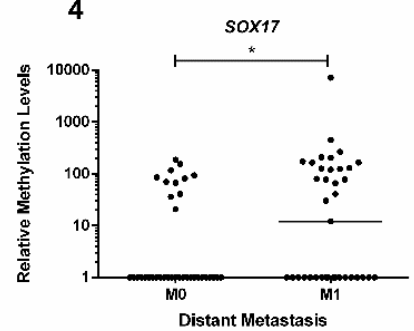

Figure 2. Scatter plot of (A) (1) RASSF1A promoter's methylation levels in PR-positive or negative breast cancer $(\mathrm{BrC})$ patients (Negative $n=24$, Positive $n=94$ ); (2) RAR $\beta 2$ promoter's methylation levels between regional node $(\mathrm{N})$ status in $\mathrm{BrC}$ patients (Negative $n=65$, Positive $n=43$ ), (B) (1) APC; (2) SEPT9; (3) SHOX2 and (4) SOX17 promoter's methylation levels between metastatic (M1) and non-metastatic colorectal cancer (CRC) patients (M0) (M0 $n=66, \mathrm{M} 1 n=6)$, and (C) (1) APC and (2) $R A R \beta 2$ promoters methylation levels for histological subtype [Adenocarcinoma $n=56$, Small-cell Lung Cancer (SCLC) $n=8$ ], (3) RASSF1A promoter's methylation levels for regional node (N) status in lung cancer $(\mathrm{LC})$ patients (Negative $=27$, Positive $=45$ ) and (4) SOX17 promoter's methylation levels between metastatic (M1) and non-metastatic LC patients (M0) (M0 $n=36, \mathrm{M} 1 n=37)$. Mann Whitney $\mathrm{U}$, n.s. $p>0.05,{ }^{*} p<0.05,{ }^{* *} p<0.01,{ }^{* * *} p<0.0001$. Black horizontal line represents the methylation levels' median. 


\subsection{Biomarker Performance in ccfDNA}

Gene promoters disclosing significantly higher methylation levels in cancer patients vs. controls were selected for assessment of BrC, CRC or LC detection performance in ccfDNA. APC, FOXA1 and RASSF1A individually depicted sensitivity over $20 \%$ and specificity greater than $70 \%$, for all cancers. FOXA1 displayed the highest sensitivity ( $39 \%$ for $\mathrm{BrC}, 50 \%$ for CRC and $73 \%$ for LC). Overall RASSF1A disclosed the highest specificity (over 98\%) for all three cancer types and SEPT9 displayed $100 \%$ specificity for CRC detection. SCGB3A1 detected BrC and CRC with over $20 \%$ sensitivity, whereas $R A R \beta 2$ and SOX17 displayed specificity higher than $90 \%$ for CRC and LC detection (Supplementary Tables S2-S4). Since APC, FOXA1 and RASSF1A were biomarkers common to BrC, CRC and LC, they were further tested as gene panel for cancer detection (designated "PanCancer"), whereas RAR $\beta 2$, SCGB3A1, SEPT9 and SOX17 were considered a gene panel for discrimination of primary cancer localization ("CancerType" panel). In ccfDNA, the "PanCancer" panel correctly detected 183 out of 253 cancer cases, corresponding to $72.4 \%$ sensitivity, $73.5 \%$ specificity and $72.8 \%$ accuracy (Table 2 , Figure 3).

Table 2. Biomarker performance detection of "PanCancer" panel (APC, FOXA1 and RASSF1A) in ccfDNA.

\begin{tabular}{cc}
\hline Validity Estimates & PanCancer \\
\hline Sensitivity $\%$ & 72.4 \\
\hline Specificity $\%$ & 73.5 \\
\hline Positive Predictive Value $\%$ & 87.1 \\
\hline Negative Predictive Value $\%$ & 52.1 \\
\hline Accuracy $\%$ & 72.8 \\
\hline
\end{tabular}

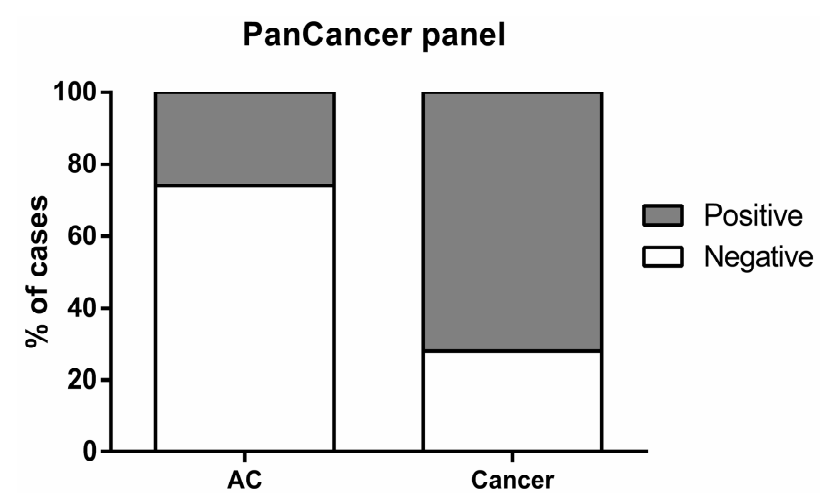

Figure 3. Percentage of cases identified by "PanCancer" panel in cancer samples (Positive 72\%, Negative 28\%) and asymptomatic controls (ACs) (Positive 26\%, Negative 74\%).

Furthermore, "PanCancer" panel detected CRC stages 0, I and II with 78.4\% sensitivity, 69.9\% specificity, 48.3\% PPV, 90.0\% NPV and 72.1\% accuracy and early LC with $85.7 \%$ sensitivity, $75.7 \%$ specificity, $41.9 \%$ PPV, 96.3\% NPV and 77.4\% accuracy. However only 37 CRC samples and 21 LC samples were used for this estimation, thus these results need further validation. Using the "CancerType" panel, three methylated genes might be used to indicate the most likely primary location of the tumor detected by the "PanCancer" panel (Tables 3 and 4). SCGB3A1 detected BrC with $80.0 \%$ specificity, whereas SEPT9 methylation detected CRC with $98.9 \%$ specificity and SOX17 detected LC with $85.1 \%$ specificity (Table 4). RARß2 was not further included in "CancerType" since it was not useful for discrimination between CRC and LC. The results of the "CancerType" panel could, then, be used to select the best strategy for identification of primary localization (mammography, colonoscopy or LD-CT) (Figure 4). 
Table 3. Methylated gene promoter combinations for $\mathrm{BrC}, \mathrm{CRC}$ and $\mathrm{LC}$ discrimination using the "CancerType" panel.

\begin{tabular}{cccc}
\hline Gene & BrC & CRC & LC \\
\hline SCGB3A1 & + & - & - \\
\hline SEPT9 & - & + & - \\
\hline SOX17 & - & - & +
\end{tabular}

"+" indicates a higher probability to find that cancer; "_" denotes that there is a low probability for that cancer type be present. Abbreviations: BrC-Breast Cancer; CRC—Colorectal Cancer; LC-Lung Cancer.

Table 4. Performance of gene promoter combinations for discrimination among BrC, CRC and LC.

\begin{tabular}{|c|c|c|c|}
\hline Gene & Sensitivity \% & Specificity \% & Accuracy \% \\
\hline \multicolumn{4}{|c|}{$\mathrm{BrC}$} \\
\hline SCGB3A1 & 16.8 & 80.0 & 53.0 \\
\hline SEPT9 & - & - & - \\
\hline SOX17 & - & - & - \\
\hline \multicolumn{4}{|c|}{ CRC } \\
\hline SCGB3A1 & - & - & - \\
\hline SEPT9 & 11.1 & 98.9 & 73.9 \\
\hline SOX17 & - & - & - \\
\hline \multicolumn{4}{|c|}{ LC } \\
\hline SCGB3A1 & - & - & - \\
\hline SEPT9 & - & - & - \\
\hline SOX17 & 39.4 & 85.1 & 71.9 \\
\hline
\end{tabular}

Abbreviations: BrC-Breast Cancer; CRC—Colorectal Cancer; LC—Lung Cancer.

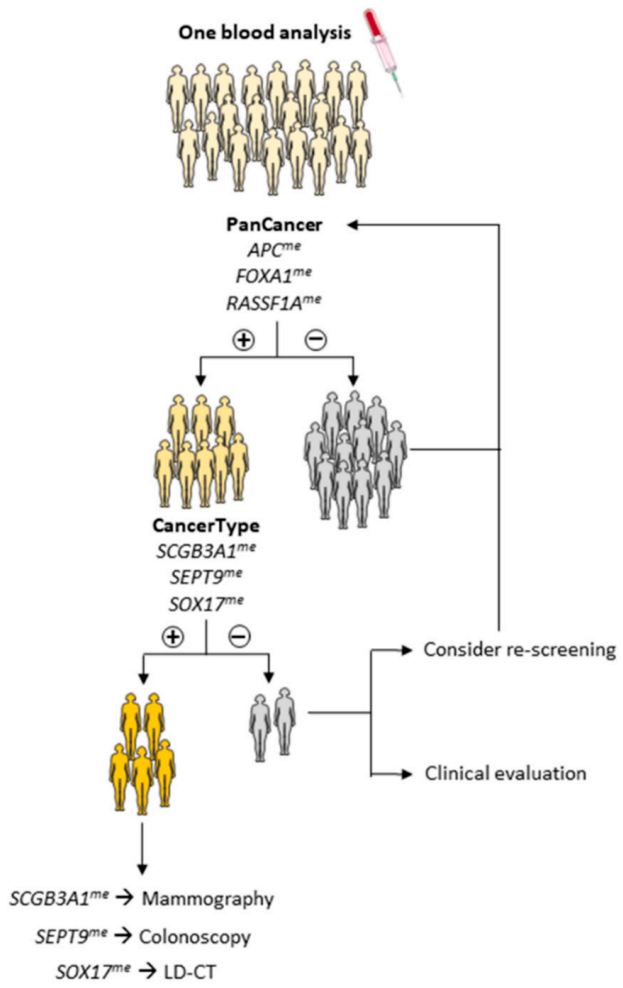

Figure 4. Schematic representation of a proposed algorithm for screening and management of breast, colorectal and lung cancers using the methylation tests. If "PanCancer" panel was positive, "CancerType" panel would be performed in order to determine the cancer type present. After "CancerType" panel, exams such as mammography, colonoscopy or low-dose computed tomography (LD-CT) would be executed to confirm the diagnosis. If "PanCancer" panel was negative, a re-screening would be proposed, whereas if "CancerType" panel was negative, a clinical evaluation or a re-screening would be considered as options. 


\section{Discussion}

$\mathrm{BrC}, \mathrm{CRC}$ and LC are the most incident and lethal neoplasms among women in developed regions of the globe [1] and screening programs may decrease mortality through increased detection of early stage disease [4,6,7]. Mammography and colonoscopy are gold-standard for $\mathrm{BrC}$ and CRC screening, whereas LD-CT is recommended for high-risk smokers' screening [4,30,31]. Notwithstanding, these screening tools have significant limitations, comprising risk of overdiagnosis/overtreatment, invasiveness and high cost, entailing low compliance, and suboptimal specificity, requiring further testing and increasing suspects' anxiety [5,7]. Hence, low-invasive screening strategies, capable of better triaging cancer suspects for testing with highly specific methods are an important clinical challenge. Owing to the ubiquity and cancer-specificity of selected aberrant gene promoter methylation, enabling successful cancer detection in liquid biopsies [13], we assessed the feasibility of ccfDNA analysis using multiplex qMSP for simultaneous BrC, CRC and LC detection in women.

Candidate genes were selected based on an extensive and critical literature review [15,17,22-29], including our previously published results $[16,18]$, and, globally, our findings are mostly in line with previous publications. For BrC, we confirmed APC, FOXA1, RASSF1A and SCGB3A1 hypermethylation in ccfDNA, in accordance with published studies $[15,23,24]$, whereas $R A R \beta 2$ methylation findings paralleled some previous studies [15,32], but not others, either in tissue [33], fine-needle washings [18] or serum [23,34]. Differences in methodology [34], population [23] and/or biological sample type $[18,33]$ likely explain these dissimilarities. Furthermore, SOX17 promoter has been reported as aberrantly methylated in ccfDNA and CTCs from $\mathrm{BrC}$ patients' [35], albeit its $\mathrm{BrC}$ biomarker potential requires further investigation. As for $\mathrm{CRC}$, the significantly higher $A P C$, FOXA1, RAR 22 , RASSF1A, SCGB3A1, SEPT9 and SOX17 methylation levels in cancer patients are in line with previous publications [16,27,36-39], although divergent results have been reported for MGMT [16,27]. Concerning LC, and except for SHOX2, our results are in accordance with previous studies $[17,28,29,40,41]$. To the best of our knowledge, this is the first study disclosing FOXA1 methylation in CRC and LC patients' ccfDNA.

Although several gene methylation panels have been proposed for specific cancer detection using ccfDNA $[15,17,24,26]$, our main goal was to devise a gene panel enabling the simultaneous detection of the three most common cancers among women, thus potentially increasing the cost-effectiveness of a methylation-based screening test. Remarkably, similar sensitivity and specificity was disclosed by the "PanCancer" panel (APC, FOXA1 and RASSF1A) compared to other gene methylation panels proposed for individual $\mathrm{BrC}, \mathrm{CRC}$ and LC detection $[15,17,24,26]$. Compared to mammography, "PanCancer" discloses lower sensitivity and specificity [2], but it may be advantageous for triaging women for mammographic screening, eventually decreasing cumulative radiation exposure and costs, while increasing women's compliance. It would be interesting to ascertain whether the molecular test might provide more accurate screening results than mammography in women with high breast density, for which mammography is mostly ineffective. Optimally performed colonoscopy detects CRC with 58-75\% sensitivity, depending on the localization of the tumor [42], and allows for confirmatory tumor biopsy and polyp removal [30]. Nevertheless, it is a costly, invasive approach that requires prior preparation and sedation [30], whereas FOBT tests are non-invasive but have limited sensitivity and specificity [30]. The "PanCancer" panel disclosed similar detection performance to colonoscopy and superior to fecal occult blood tests, constituting a minimally-invasive test, amenable for screening. Finally, the "PanCancer" panel clearly outperformed LD-CT for LC detection and might be favorably used in a pre-screening context, to better identify high-risk suspects of harboring LC (Figure 4). Interestingly, the "PanCancer" panel detected stage I and II LC with a high sensitivity and specificity, and may, thus, constitute a novel option for LC early detection. Furthermore, it is likely that lesions that are difficult to diagnose by imaging techniques might be detectable using the "PanCancer" panel as Shan et al. have previously demonstrated that a methylation-based panel detected small breast tumors $(<1 \mathrm{~cm})$ with higher sensitivity than mammography [24]. 
Identifying the putative cancer primary localization following a positive "PanCancer" panel result constitutes the next challenge. Based on the individual performance of the remainder gene promoters tested, we proposed another panel ("CancerType") which attempts to indicate the most likely topography of the primary tumor. To increase cost-effectiveness, this panel would only be performed in "PanCancer" positive cases, allowing cancer suspects to be directed for mammography, colonoscopy or LD-CT. Although "CancerType" genes individually display low sensitivity, the main goal of this panel is to discriminate among the three cancer types, requiring high specificity. Risk factors should be also considered (e.g., familial history of $\mathrm{BrC}$ or $\mathrm{CRC}$, tobacco exposure) to improve the detection strategy. In cases in which no tumor is found, looking for the remaining possible localizations should be guided according to clinical evaluation. Repeat testing after a defined time could also be considered. It is difficult, however, to estimate how results of the "CancerType" panel would perform in a real setting as it assessment implies a carefully designed study with relatively long follow-up period.

Some interesting clinicopathological correlates with gene promoter methylation status were disclosed. The association of RASSF1A promoter methylation with PR status parallels previous reports [43] and higher $R A R \beta 2$ methylation in node-positive $\mathrm{BrC}$ is in line with previous findings in sentinel lymph node metastasis [44] and the correlation between primary BrC and lymph node metastasis tissues [45]. Furthermore, some of the tested candidate genes might also convey relevant prognostic information, as APC, SEPT9, SHOX2 and SOX17 methylation levels were increased in CRC patients with distant metastasis. Interestingly, a recent study disclosed higher SEPT9 and SHOX2 methylation levels in ccfDNA of CRC patients with distant metastasis and advanced stages [46]. Moreover, a correlation between APC methylation and more advanced CRC stage was previously established in CRC tissue analysis [47] and APC methylation was also found in CRC hepatic metastasis [48]. Another interesting finding was the higher APC and RAR $\beta 2$ methylation levels in patients with SCLC vs. lung adenocarcinoma. Recently, a microRNA-based test (miRview $\left.{ }^{\circledR}\right)$ test was approved for discrimination among LC subtypes [49], based on analysis of pre-operative biopsies, which might be difficult to obtain. Thus, gene promoter methylation assessment in ccfDNA might prove advantageous in lung tumors with difficult access, since SCLC requires a specific treatment regimen and is associated with a worse prognosis [50]. Furthermore, an association between RASSF1A methylation and node-positive LC patients was found, which is in accordance with previous publications demonstrating higher RASSF1A methylation levels in more advanced tumor stage, associating with local recurrence and worse prognosis in LC patients [51,52]. Finally, SOX17 promoter methylation levels are associated with distant metastasis, in agreement with previous studies using plasma samples from LC patients [40].

The main limitations of this study are the limited number of samples tested and the lack of long-term follow-up, which would be required to determine whether asymptomatic controls testing positive would subsequently develop $\mathrm{BrC}, \mathrm{CRC}$ or LC. These limitations also preclude an accurate estimate of the use of the two gene panels in a "real world" scenario. Nevertheless, it should be emphasized that our proposal is innovative and might foster the development of more accurate and cost-effective tools for BrC, CRC and LC screening.

\section{Materials and Methods}

\subsection{Patients and Samples Collection}

Blood samples were collected from female patients $(n=253)$ with BrC $(n=108)$, CRC $(n=72)$ or LC $(n=73)$ at the time of diagnosis, prior to any treatment, and from female healthy donors [(asymptomatic controls (AC)] older than 45 years $(n=103)$, at the Portuguese Oncology Institute of Porto, Portugal. Plasma was separated from blood harvested in EDTA tubes by centrifuging at $2000 \mathrm{rpm}$ for $10 \mathrm{~min}$ and immediately frozen at $-80^{\circ} \mathrm{C}$. Relevant clinical and pathological data was 
retrieved from clinical charts and an anonymized database was constructed for analysis purposes (Table 1, Supplementary Table S5).

This study was approved by the institutional review board (Comissão de Ética para a Saúde-CES 120/2015) of Portuguese Oncology Institute of Porto, Portugal. All patients and healthy donors enrolled in this study provided written informed consent, in accordance with the Declaration of Helsinki ethical principles.

\subsection{Ccf-DNA Extraction, Sodium-Bisulfite Modification and Whole Genome Amplification (WGA)}

QIAamp MinElute ccfDNA (Qiagen, Hilden, Germany) was used for ccfDNA extraction from $2-3 \mathrm{~mL}$ of plasma, according to manufacturers' instructions, subsequently eluted in $20 \mu \mathrm{L}$ of sterile distilled water and stored at $-20{ }^{\circ} \mathrm{C}$ until further use. All ccfDNA samples were bisulfite-modified using EZ DNA Methylation-Gold ${ }^{\mathrm{TM}}$ Kit (Zymo Research, Irvine, CA, USA) according to the manufacturer's recommendations. Twenty $\mu \mathrm{L}$ of extracted ccfDNA and $1 \mu \mathrm{g}$ of CpGenome ${ }^{\mathrm{TM}}$ Universal Methylated DNA (Merck Millipore, Burlington, MA, USA) were used for sodium-bisulfite modification. The bisulfite-converted ccfDNA was eluted in $10 \mu \mathrm{L}$ of sterile distilled water and stored at $-80^{\circ} \mathrm{C}$ until further use. WGA of $10 \mu \mathrm{L}$ sodium-bisulfite modified ccfDNA was carried out using the EpiTect Whole Bisulfitome Kit (Qiagen, Hilden, Germany) according to manufacturer's recommendations [53,54]. Amplified DNA was diluted in $25 \mu \mathrm{L}$ of sterile distilled water, in a final volume of $65 \mu \mathrm{L}$, and stored at $-20^{\circ} \mathrm{C}$ until further use. Extracted ccfDNA, amplified DNA and sodium-bisulfite converted DNA were quantified using Qubit 2 Fluorometer (Invitrogen, Carlsbad, CA, USA) following manufacturer's instructions.

\subsection{Multiplex $q M S P$}

The nine genes (APC, FOXA1, MGMT, RARß2, RASSF1A, SCGB3A1, SEPT9, SHOX2 and SOX17) promoter methylation levels were assessed by multiplex qMSP, using amplified DNA as template $[25,55]$. Primers and probes specifically designed for the modified gene sequence plus the fluorochromes and quenchers used for each probe are listed in Supplementary Table S6. $\beta$-Actin was used as reference gene to normalize the DNA quantity of each sample [18]. $6 \mu \mathrm{L}$ of WGA amplified DNA and Xpert Fast Probe (GRiSP, Porto, Portugal) were used in each multiplex qMSP reaction. Multiplex qMSP assays were carried out in 96-well plates in triplicate using a 7500 Sequence Detector (Applied Biosystems, Perkin Elmer, CA, USA). Sterile distilled water subjected to WGA was used a negative control and included in all plates. WGA amplified CpGenome ${ }^{\mathrm{TM}}$ Universal Methylated DNA (Merck Millipore, Burlington, MA, USA) subjected to six serial dilutions ( $5 \times$ factor dilution) was used to generate a standard curve in each plate, allowing for relative quantification and PCR efficiency evaluation. Efficiency values above $90 \%$ were considered. Relative methylation levels were determined as the ratio between the mean methylation levels of each gene and the respective value for $\beta$-Actin (the housekeeping gene), multiplied by 1000 for easier tabulation.

\subsection{Statistical Analysis}

Non-parametric tests were used to compare methylation levels of each gene promoter between cases and respective controls and to evaluate associations with clinicopathological features. Mann-Whitney U test was used for comparisons between two groups and Kruskall-Wallis test for three or more groups, followed by Mann-Whitney U test with Bonferroni's correction for pairwise comparisons. Correlations between methylation levels and age were assessed by Spearman nonparametric correlation test. A $p$ value $<0.05$ was considered statistically significant.

For each gene, samples were categorized as methylated or unmethylated based on cut-off value determined using Youden's J index (value combining highest sensitivity and specificity), through ROC curve analysis [56]. A positive result was considered when a sample was classified as methylated and negative when unmethylated. Validity estimates [sensitivity, specificity, positive predictive value (PPV), negative predictive value (NPV), and accuracy] were calculated to assess biomarker 
performance. Gene panels were constructed to maximize detection performance, considering a positive result whenever at least one gene promoter was methylated. The validity estimates for "PanCancer" panel were determined by assembling all cancer samples including BrC, CRC and LC $(n=253)$ vs. AC samples $(n=103)$. For "CancerType" panel, the cut-offs were determined by comparing each tumor type with the other two. A multiple ROC curves via resampling analysis was performed in order to calculate the validity estimates for "PanCancer" and "CancerType" panels, using a similar methodology previously described [57]. Briefly, the samples were randomly divided in a training $(70 \%)$ and validation (30\%) sets. The cut-off value comprising the highest sensitivity and specificity was estimated in the training set and the validity estimates were calculated in the validation set using that cut-off. This procedure was repeated 1000 times, and the mean of the sensitivities and specificities was calculated. These calculations were performed using R v3.4.4. Two-tailed $p$-values calculation and other ROC curve analyses were performed using a computer assisted program (SPSS Version 24.0, Chicago, IL, USA). Graphics were assembled with GraphPad 6 Prism (GraphPad Software, La Jolla, CA, USA).

\section{Conclusions}

A selected gene promoter methylation assessment in ccfDNA is shows promise for simultaneous screening of BrC, CRC and LC, the major causes of cancer-related morbidity and mortality in women. The panels might complement current screening modalities, perfect the triage of cancer suspects, and increase compliance and cost-effectiveness. Large-scale studies are now required to validate these findings and define the best algorithm for clinical application of these minimally-invasive methylation-based tests.

Supplementary Materials: The following are available online at http:/ /www.mdpi.com/2072-6694/10/10/357/ s1, Table S1: Promoters' methylation levels cut-off values used to categorize BrC, CRC and LC samples vs. AC samples used for validity estimates calculation in Figure 1 and Tables S2-S4. Table S2: Biomarker performance of each promoter's gene methylation for BrC detection in ccfDNA, Table S3: Biomarker performance of each promoter's gene methylation for CRC detection in ccfDNA. Table S4: Biomarker performance of each promoter's gene methylation for LC detection in ccfDNA liquid biopsies. Table S5: Additional clinicopathological features of breast cancer $(\mathrm{BrC})$ patients' plasma samples used in this study, Table S6: Primers and probes sequences with respective fluorochrome and quencher

Author Contributions: S.P.N. performed DNA extraction, multiplex qMSP, analyzed data and drafted the manuscript. C.M.-B. and S.S. assisted in data analysis. S.P.d.S., M.S. and T.D. collected follow-up data. I.P., J.O. and L.R. assisted in patients' enrolment for plasma samples' collection. L.A. and J.R. assisted in statistical analyses. R.H. and C.J. designed and supervised the study and revised the manuscript. All authors read and approved the final manuscript.

Funding: This work was supported by a grant from Research Center of Portuguese Oncology Institute of Porto (PI 74-CI-IPOP-19-2016). C.M.-B. was supported by Núcleo Regional da Madeira da Liga Portuguesa Contra o Cancro \& Diário de Notícias. S.S. is supported by a PhD fellowship IPO/ESTIMA-1 NORTE-01-0145-FEDER-000027. J.R. is supported by a fellowship PI 110-CI-IPOP89 2018-CES 329-017.

Acknowledgments: We thank all patients and healthy donors who accepted to participate in this study. We acknowledge the Nursing Staff, in particular to Berta Reis, from Department of Laboratory Medicine, Portuguese Oncology Institute of Porto that participated in sample collection. Without them this study would not be possible.

Conflicts of Interest: The authors declare no conflict of interest.

\section{References}

1. Ferlay, J.; Soerjomataram, I.; Dikshit, R.; Eser, S.; Mathers, C.; Rebelo, M.; Parkin, D.M.; Forman, D.; Bray, F. Cancer incidence and mortality worldwide: Sources, methods and major patterns in GLOBOCAN 2012. Int. J. Cancer 2015, 136, E359-E386. [CrossRef] [PubMed]

2. Sickles, E.A.; D'Orsi, C.J. How should screening breast US be audited? The BI-RADS perspective. Radiology 2014, 272, 316-320. [CrossRef] [PubMed]

3. Holland, R.; Mravunac, M.; Hendriks, J.H.; Bekker, B.V. So-called interval cancers of the breast. Pathologic and radiologic analysis of sixty-four cases. Cancer 1982, 49, 2527-2533. [CrossRef] 
4. Tabar, L.; Vitak, B.; Chen, H.H.; Yen, M.F.; Duffy, S.W.; Smith, R.A. Beyond randomized controlled trials: Organized mammographic screening substantially reduces breast carcinoma mortality. Cancer 2001, 91, 1724-1731. [CrossRef]

5. Independent UK Panel on Breast Cancer Screening. The benefits and harms of breast cancer screening: An independent review. Lancet 2012, 380, 1778-1786. [CrossRef]

6. Pawa, N.; Arulampalam, T.; Norton, J.D. Screening for colorectal cancer: Established and emerging modalities. Nat. Rev. Gastroenterol. Hepatol. 2011, 8, 711-722. [CrossRef] [PubMed]

7. Simon, K. Colorectal cancer development and advances in screening. Clin. Interv. Aging 2016, 11, 967-976. [CrossRef] [PubMed]

8. Plumb, A.A.; Halligan, S. Colorectal cancer screening. Semin. Roentgenol. 2015, 50, 101-110. [CrossRef] [PubMed]

9. Prosch, H.; Schaefer-Prokop, C. Screening for lung cancer. Curr. Opin. Oncol. 2014, 26, 131-137. [CrossRef] [PubMed]

10. Infante, M.; Cavuto, S.; Lutman, F.R.; Passera, E.; Chiarenza, M.; Chiesa, G.; Brambilla, G.; Angeli, E.; Aranzulla, G.; Chiti, A.; et al. Long-Term Follow-up Results of the DANTE Trial, a Randomized Study of Lung Cancer Screening with Spiral Computed Tomography. Am. J. Respir. Crit. Care Med. 2015, 191, 1166-1175. [CrossRef] [PubMed]

11. National Lung Screening Trial Research Team; Aberle, D.R.; Adams, A.M.; Berg, C.D.; Black, W.C.; Clapp, J.D.; Fagerstrom, R.M.; Gareen, I.F.; Gatsonis, C.; Marcus, P.M.; et al. Reduced Lung-Cancer Mortality with Low-Dose Computed Tomographic Screening. N. Engl. J. Med. 2011, 365, 395-409. [CrossRef] [PubMed]

12. Lao, V.V.; Grady, W.M. Epigenetics and colorectal cancer. Nat. Rev. Gastroenterol. Hepatol. 2011, 8, 686-700. [CrossRef] [PubMed]

13. Costa-Pinheiro, P.; Montezuma, D.; Henrique, R.; Jeronimo, C. Diagnostic and prognostic epigenetic biomarkers in cancer. Epigenomics 2015, 7, 1003-1015. [CrossRef] [PubMed]

14. Han, X.; Wang, J.; Sun, Y. Circulating tumor DNA as biomarkers for cancer detection. Genom. Proteom. Bioinf. 2017, 15, 59-72. [CrossRef] [PubMed]

15. Hoque, M.O.; Feng, Q.; Toure, P.; Dem, A.; Critchlow, C.W.; Hawes, S.E.; Wood, T.; Jeronimo, C.; Rosenbaum, E.; Stern, J.; et al. Detection of aberrant methylation of four genes in plasma DNA for the detection of breast cancer. J. Clin. Oncol. 2006, 24, 4262-4269. [CrossRef] [PubMed]

16. Freitas, M.; Ferreira, F.; Carvalho, S.; Silva, F.; Lopes, P.; Antunes, L.; Salta, S.; Diniz, F.; Santos, L.L.; Videira, J.F.; et al. A novel DNA methylation panel accurately detects colorectal cancer independently of molecular pathway. J. Transl. Med. 2018, 16, 45. [CrossRef] [PubMed]

17. Begum, S.; Brait, M.; Dasgupta, S.; Ostrow, K.L.; Zahurak, M.; Carvalho, A.L.; Califano, J.A.; Goodman, S.N.; Westra, W.H.; Hoque, M.O.; et al. An epigenetic marker panel for detection of lung cancer using cell-free serum DNA. Clin. Cancer Res. 2011, 17, 4494-4503. [CrossRef] [PubMed]

18. Jeronimo, C.; Costa, I.; Martins, M.C.; Monteiro, P.; Lisboa, S.; Palmeira, C.; Henrique, R.; Teixeira, M.R.; Lopes, C. Detection of gene promoter hypermethylation in fine needle washings from breast lesions. Clin. Cancer Res. 2003, 9, 3413-3417. [PubMed]

19. Weiss, G.; Schlegel, A.; Kottwitz, D.; Konig, T.; Tetzner, R. Validation of the SHOX2/PTGER4 DNA Methylation Marker Panel for Plasma-Based Discrimination between Patients with Malignant and Nonmalignant Lung Disease. J. Thorac. Oncol. 2017, 12, 77-84. [CrossRef] [PubMed]

20. Potter, N.T.; Hurban, P.; White, M.N.; Whitlock, K.D.; Lofton-Day, C.E.; Tetzner, R.; Koenig, T.; Quigley, N.B.; Weiss, G. Validation of a Real-Time PCR-Based Qualitative Assay for the Detection of Methylated SEPT9 DNA in Human Plasma. Clin. Chem. 2014, 60, 1183-1191. [CrossRef] [PubMed]

21. Liu, L.; Toung, J.M.; Jassowicz, A.F.; Vijayaraghavan, R.; Kang, H.; Zhang, R.; Kruglyak, K.M.; Huang, H.J.; Hinoue, T.; Shen, H.; et al. Targeted methylation sequencing of plasma cell-free DNA for cancer detection and classification. Ann. Oncol. 2018, 29, 1445-1453. [CrossRef] [PubMed]

22. Warton, K.; Samimi, G. Methylation of cell-free circulating DNA in the diagnosis of cancer. Front. Mol. Biosci. 2015, 2, 13. [CrossRef] [PubMed]

23. Kim, J.H.; Shin, M.H.; Kweon, S.S.; Park, M.H.; Yoon, J.H.; Lee, J.S.; Choi, C.; Fackler, M.J.; Sukumar, S. Evaluation of promoter hypermethylation detection in serum as a diagnostic tool for breast carcinoma in Korean women. Gynecol. Oncol. 2010, 118, 176-181. [CrossRef] [PubMed] 
24. Shan, M.; Yin, H.; Li, J.; Li, X.; Wang, D.; Su, Y.; Niu, M.; Zhong, Z.; Wang, J.; Zhang, X.; et al. Detection of aberrant methylation of a six-gene panel in serum DNA for diagnosis of breast cancer. Oncotarget 2016, 7, 18485-18494. [CrossRef] [PubMed]

25. He, Q.; Chen, H.Y.; Bai, E.Q.; Luo, Y.X.; Fu, R.J.; He, Y.S.; Jiang, J.; Wang, H.Q. Development of a multiplex MethyLight assay for the detection of multigene methylation in human colorectal cancer. Cancer Genet. Cytogenet. 2010, 202, 1-10. [CrossRef] [PubMed]

26. Roperch, J.P.; Incitti, R.; Forbin, S.; Bard, F.; Mansour, H.; Mesli, F.; Baumgaertner, I.; Brunetti, F.; Sobhani, I. Aberrant methylation of NPY, PENK, and WIF1 as a promising marker for blood-based diagnosis of colorectal cancer. BMC Cancer 2013, 13, 566. [CrossRef] [PubMed]

27. Lee, B.B.; Lee, E.J.; Jung, E.H.; Chun, H.K.; Chang, D.K.; Song, S.Y.; Park, J.; Kim, D.H. Aberrant methylation of APC, MGMT, RASSF2A, and Wif-1 genes in plasma as a biomarker for early detection of colorectal cancer. Clin. Cancer Res. 2009, 15, 6185-6191. [CrossRef] [PubMed]

28. Hulbert, A.; Jusue-Torres, I.; Stark, A.; Chen, C.; Rodgers, K.; Lee, B.; Griffin, C.; Yang, A.; Huang, P.; Wrangle, J.; et al. Early Detection of Lung Cancer Using DNA Promoter Hypermethylation in Plasma and Sputum. Clin. Cancer Res. 2017, 23, 1998-2005. [CrossRef] [PubMed]

29. Ostrow, K.L.; Hoque, M.O.; Loyo, M.; Brait, M.; Greenberg, A.; Siegfried, J.M.; Grandis, J.R.; Gaither Davis, A.; Bigbee, W.L.; Rom, W.; et al. Molecular analysis of plasma DNA for the early detection of lung cancer by quantitative methylation-specific PCR. Clin. Cancer Res. 2010, 16, 3463-3472. [CrossRef] [PubMed]

30. Bailey, J.R.; Aggarwal, A.; Imperiale, T.F. Colorectal Cancer Screening: Stool DNA and Other Noninvasive Modalities. Gut Liver 2016, 10, 204-211. [CrossRef] [PubMed]

31. Crino, L.; Weder, W.; Van Meerbeeck, J.; Felip, E. Early stage and locally advanced (non-metastatic) non-small-cell lung cancer: ESMO Clinical Practice Guidelines for diagnosis, treatment and follow-up. Ann. Oncol. 2010, 21, v103-v115. [CrossRef] [PubMed]

32. Martinez-Galan, J.; Torres, B.; Del Moral, R.; Munoz-Gamez, J.A.; Martin-Oliva, D.; Villalobos, M.; Nunez, M.I.; Luna Jde, D.; Oliver, F.J.; Ruiz de Almodovar, J.M. Quantitative detection of methylated ESR1 and 14-3-3-sigma gene promoters in serum as candidate biomarkers for diagnosis of breast cancer and evaluation of treatment efficacy. Cancer Biol. Ther. 2008, 7, 958-965. [CrossRef] [PubMed]

33. Fackler, M.J.; McVeigh, M.; Mehrotra, J.; Blum, M.A.; Lange, J.; Lapides, A.; Garrett, E.; Argani, P.; Sukumar, S. Quantitative multiplex methylation-specific PCR assay for the detection of promoter hypermethylation in multiple genes in breast cancer. Cancer Res. 2004, 64, 4442-4452. [CrossRef] [PubMed]

34. Yamamoto, N.; Nakayama, T.; Kajita, M.; Miyake, T.; Iwamoto, T.; Kim, S.J.; Sakai, A.; Ishihara, H.; Tamaki, Y.; Noguchi, S. Detection of aberrant promoter methylation of GSTP1, RASSF1A, and RARbeta2 in serum DNA of patients with breast cancer by a newly established one-step methylation-specific PCR assay. Breast Cancer Res. 2012, 132, 165-173. [CrossRef] [PubMed]

35. Chimonidou, M.; Strati, A.; Malamos, N.; Georgoulias, V.; Lianidou, E.S. SOX17 promoter methylation in circulating tumor cells and matched cell-free DNA isolated from plasma of patients with breast cancer. Clin. Chem. 2013, 59, 270-279. [CrossRef] [PubMed]

36. Miladi-Abdennadher, I.; Abdelmaksoud-Damak, R.; Ayadi, L.; Khabir, A.; Frikha, F.; Kallel, L.; Amouri, A.; Frikha, M.; Sellami-Boudawara, T.; Gargouri, A.; et al. Hypermethylation of RARbeta2 correlates with high COX-2 expression and poor prognosis in patients with colorectal carcinoma. Tumour Biol. 2010, 31, 503-511. [CrossRef] [PubMed]

37. Van Engeland, M.; Roemen, G.M.; Brink, M.; Pachen, M.M.; Weijenberg, M.P.; de Bruine, A.P.; Arends, J.W.; van den Brandt, P.A.; de Goeij, A.F.; Herman, J.G. K-ras mutations and RASSF1A promoter methylation in colorectal cancer. Oncogene 2002, 21, 3792-3795. [CrossRef] [PubMed]

38. Rasmussen, S.L.; Krarup, H.B.; Sunesen, K.G.; Johansen, M.B.; Stender, M.T.; Pedersen, I.S.; Madsen, P.H.; Thorlacius-Ussing, O. Hypermethylated DNA, a circulating biomarker for colorectal cancer detection. PLoS ONE 2017, 12, e0180809. [CrossRef] [PubMed]

39. Silva, A.L.; Dawson, S.N.; Arends, M.J.; Guttula, K.; Hall, N.; Cameron, E.A.; Huang, T.H.; Brenton, J.D.; Tavare, S.; Bienz, M.; et al. Boosting Wnt activity during colorectal cancer progression through selective hypermethylation of Wnt signaling antagonists. BMC Cancer 2014, 14, 891. [CrossRef] [PubMed]

40. Balgkouranidou, I.; Chimonidou, M.; Milaki, G.; Tsaroucha, E.; Kakolyris, S.; Georgoulias, V.; Lianidou, E. SOX17 promoter methylation in plasma circulating tumor DNA of patients with non-small cell lung cancer. Clin. Chem. Lab. Med. 2016, 54, 1385-1393. [CrossRef] [PubMed] 
41. Kneip, C.; Schmidt, B.; Seegebarth, A.; Weickmann, S.; Fleischhacker, M.; Liebenberg, V.; Field, J.K.; Dietrich, D. SHOX2 DNA methylation is a biomarker for the diagnosis of lung cancer in plasma. J. Thorac. Oncol. 2011, 6, 1632-1638. [CrossRef] [PubMed]

42. Whitlock, E.P.; Lin, J.; Liles, E.; Beil, T.; Fu, R.; O'Connor, E.; Thompson, R.N.; Cardenas, T. Screening for Colorectal Cancer: An Updated Systematic Review; Agency for Healthcare Research and Quality: Rockville, MD, USA, 2008.

43. Kajabova, V.; Smolkova, B.; Zmetakova, I.; Sebova, K.; Krivulcik, T.; Bella, V.; Kajo, K.; Machalekova, K.; Fridrichova, I. RASSF1A Promoter Methylation Levels Positively Correlate with Estrogen Receptor Expression in Breast Cancer Patients. Transl. Oncol. 2013, 6, 297-304. [CrossRef] [PubMed]

44. Shinozaki, M.; Hoon, D.S.; Giuliano, A.E.; Hansen, N.M.; Wang, H.J.; Turner, R.; Taback, B. Distinct hypermethylation profile of primary breast cancer is associated with sentinel lymph node metastasis. Clin. Cancer Res. 2005, 11, 2156-2162. [CrossRef] [PubMed]

45. Feng, W.; Orlandi, R.; Zhao, N.; Carcangiu, M.L.; Tagliabue, E.; Xu, J.; Bast, R.C., Jr.; Yu, Y. Tumor suppressor genes are frequently methylated in lymph node metastases of breast cancers. BMC Cancer 2010, 10, 378. [CrossRef] [PubMed]

46. Bergheim, J.; Semaan, A.; Gevensleben, H.; Groening, S.; Knoblich, A.; Dietrich, J.; Weber, J.; Kalff, J.C.; Bootz, F.; Kristiansen, G.; et al. Potential of quantitative SEPT9 and SHOX2 methylation in plasmatic circulating cell-free DNA as auxiliary staging parameter in colorectal cancer: A prospective observational cohort study. Br. J. Cancer 2018, 118, 1217-1228. [CrossRef] [PubMed]

47. Li, B.-Q.; Liu, P.-P.; Zhang, C.-H. Correlation between the methylation of APC gene promoter and colon cancer. Oncol. Lett. 2017, 14, 2315-2319. [CrossRef] [PubMed]

48. Chen, J.; Rocken, C.; Lofton-Day, C.; Schulz, H.U.; Muller, O.; Kutzner, N.; Malfertheiner, P.; Ebert, M.P. Molecular analysis of APC promoter methylation and protein expression in colorectal cancer metastasis. Carcinogenesis 2005, 26, 37-43. [CrossRef] [PubMed]

49. Gilad, S.; Lithwick-Yanai, G.; Barshack, I.; Benjamin, S.; Krivitsky, I.; Edmonston, T.B.; Bibbo, M.; Thurm, C.; Horowitz, L.; Huang, Y.; et al. Classification of the four main types of lung cancer using a microRNA-based diagnostic assay. J. Mol. Diagn. 2012, 14, 510-517. [CrossRef] [PubMed]

50. Kang, H.S.; Shin, A.Y.; Yeo, C.D.; Kim, J.S.; Kim, Y.H.; Kim, J.W.; Lee, S.H. A lower level of forced expiratory volume in one second predicts the poor prognosis of small cell lung cancer. J. Thorac. Dis. 2018, 10, 2179-2185. [CrossRef] [PubMed]

51. Tomizawa, Y.; Kohno, T.; Kondo, H.; Otsuka, A.; Nishioka, M.; Niki, T.; Yamada, T.; Maeshima, A.; Yoshimura, K.; Saito, R.; et al. Clinicopathological significance of epigenetic inactivation of RASSF1A at 3p21.3 in stage I lung adenocarcinoma. Clin. Cancer Res. 2002, 8, 2362-2368. [PubMed]

52. Yanagawa, N.; Tamura, G.; Oizumi, H.; Kanauchi, N.; Endoh, M.; Sadahiro, M.; Motoyama, T. Promoter hypermethylation of RASSF1A and RUNX3 genes as an independent prognostic prediction marker in surgically resected non-small cell lung cancers. Lung Cancer 2007, 58, 131-138. [CrossRef] [PubMed]

53. Bundo, M.; Sunaga, F.; Ueda, J.; Kasai, K.; Kato, T.; Iwamoto, K. A systematic evaluation of whole genome amplification of bisulfite-modified DNA. Clin. Epigenet. 2012, 4, 22. [CrossRef] [PubMed]

54. Mill, J.; Yazdanpanah, S.; Gückel, E.; Ziegler, S.; Kaminsky, Z.; Petronis, A. Whole genome amplification of sodium bisulfite-treated DNA allows the accurate estimate of methylated cytosine density in limited DNA resources. Biotechniques 2006, 41, 603-607. [CrossRef] [PubMed]

55. Olkhov-Mitsel, E.; Zdravic, D.; Kron, K.; van der Kwast, T.; Fleshner, N.; Bapat, B. Novel multiplex MethyLight protocol for detection of DNA methylation in patient tissues and bodily fluids. Sci. Rep. 2014, 4, 4432. [CrossRef] [PubMed]

56. Schisterman, E.F.; Perkins, N.J.; Liu, A.; Bondell, H. Optimal cut-point and its corresponding Youden Index to discriminate individuals using pooled blood samples. Epidemiology 2005, 16, 73-81. [CrossRef] [PubMed]

57. Baker, S.G.; Kramer, B.S. Identifying genes that contribute most to good classification in microarrays. BMC Bioinf. 2006, 7, 407. [CrossRef] [PubMed]

(C) 2018 by the authors. Licensee MDPI, Basel, Switzerland. This article is an open access article distributed under the terms and conditions of the Creative Commons Attribution (CC BY) license (http:/ / creativecommons.org/licenses/by/4.0/). 